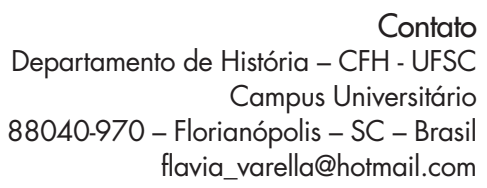

Contato

Departamento de História - CFH - UFSC

Campus Universitário

88040-970 - Florianópolis - SC - Brasil flavia_varella@hotmail.com

\section{ROBERT SOUTHEY, WILLIAM ROBERTSON E A TEORIA DOS QUATRO ESTÁGIOS NA CONSTRUÇÃO DA MACRONARRATIVA DA HISTÓRIA DOS AUTÓCTONES AMERICANOS}

\author{
Flávia Florentino Varella* \\ Universidade Federal de Santa Catarina \\ Florianópolis - Santa Catarina - Brasil
}

\title{
Resumo
}

A proposta deste artigo é analisar como a articulação da teoria dos quatro estágios serviu de pano de fundo na History of Brazil (1810-1819), escrita por Robert Southey, para o exame das populações que viviam no Brasil, rio da Prata e Paraguai. Além disso, busco mostrar a importância da History of America (1777) de William Robertson para a inserção da história americana dentro da macronarrativa da história universal através da circunscrição dos povos originários como moralmente selvagens e vivendo no estágio de caçadores e coletores. Nesse horizonte de delimitação das sociedades em bárbaras, selvagens ou civilizadas, a History of America de Robertson foi decisiva para a construção dos povos indígenas americanos como vivendo em um estado selvagem. Southey continuou explorando as maneiras e os costumes dos selvagens, realizando um significativo alargamento dos tópicos e esmiuçando as peculiaridades de diversas tribos sem, contudo, deixar de apontar seus modos

\section{Palavras chave} de subsistência, que se desenvolviam de acordo com estágios previamente delimitados.

Robert Southey - William Robertson - teoria dos quatro estágios.

* Doutora em História pela Universidade Federal do Rio Grande do Sul. Professora adjunta de Teoria da História no Departamento de História da Universidade Federal de Santa Catarina. 


\author{
Contact \\ Departamento de História - CFH - UFSC \\ Campus Universitário \\ 88040-970 - Florianópolis - SC - Brasil \\ flavia_varella@hotmail.com
}

\section{ROBERT SOUTHEY,}

WILLIAM ROBERTSON

AND THE FOUR

\section{STAGE THEORY IN}

THE CONSTRUCTION

OF THE HISTORY

OF THE NATIVE

AMERICANS'

MACRO-NARRATIVE

\author{
Flávia Florentino Varella
}

Universidade Federal de Santa Catarina

Florianópolis - Santa Catarina - Brasil

\begin{abstract}
The aim of this article is to analyze how the articulation of the four stages theory served as a backdrop in Robert Southey' History of Brazil (1810-1819) for the examination of the populations living in Brazil, Rio de la Plata and Paraguay. In addition, I try to show the importance of William Robertson' History of America (1777) for the insertion of American history within the macronarrative of world history through the constituency of indigenous peoples as morally savage and living in the stage of hunters and gatherers. In that horizon of division of societies in barbaric, savage or civilized, Robertson' History of America was decisive for the construction of the Native American people as living in a savage state. Southey continued to explore the ways and costumes of the savages, performing a significant broadening of topics and scrutinizing the peculiarities of various tribes without, however, fail to point their subsistencse mode, which were developed according to pre-defined stages.
\end{abstract}

\title{
Keywords
}

Robert Southey - William Robertson - four stages theory. 
Em 1822, no Quarterly Review, Robert Southey (1774-1843) noticiava entusiasticamente o lançamento da tradução inglesa intitulada "An account of the Abipones, an equestrian people of Paraguay", do seu admirado jesuíta Martin Dobrizhoffer (1717-1791). A tradução do latim, realizada por Sara Coleridge (1802-1852) - filha de Samuel Coleridge (1772-1834) -, contou com seu incentivo direto. ${ }^{1}$ Southey considerava que este livro não apenas abordava "a história dos (...) costumes e destino" da tribo indígena dos abipones, mas era "de todos os livros sobre a vida selvagem o mais curioso e em todos os aspectos o mais interessante". ${ }^{2}$ Avaliava o livro dessa forma, pois:

Não há partes da história mais interessantes do que aquelas que se relacionam com as transições de um estágio da sociedade para outro. Quando as nações desenvolvem-se progressivamente, cada passo do progresso tem alguma vantagem - algumas virtudes peculiares a isso; algo que, ao mesmo tempo em que nos deleita, excita algo como o remorso que isso tenha ocorrido (...) Mas, nessa parte da América do Sul que estamos agora a tratar [i.e., o Chacol, as transições não foram para o melhor: entre os índios, a mudança foi de um modo de vida selvagem para outro; entre os espanhóis, de um arrojado e aventureiro para uma brutalidade estagnada. ${ }^{3}$

Aproveitando-se do tom apocalíptico constantemente reivindicado quando tratava da história sul-americana, Southey abordava o progresso das sociedades referendando que o movimento ideal da história dava-se por estágios - excluindo possíveis benesses nas revoluções -, que gradualmente iriam substituindo rudes hábitos em prol de refinadas maneiras. Porém, a experiência colonizadora no Chaco, a seu ver, demonstrava que, mesmo após séculos, os indígenas mantinham-se na mesma situação, exceto talvez por algumas mudanças pontuais, que pouco contribuíam para a sua civilização. Igualmente o destino do colonizador não parecia muito profícuo tendo em vista a degeneração das virtudes que o haviam colocado no privilegiado papel de civilizador.

1 LOW, Dennis. The literary protégées of the lake poets. Hampshire: Ashgate, 2006, p. 107.

2 SOUTHEY, Robert. History of Brazil, vol. III. Londres: Longman, Hurst, Rees, and Orme, Paternoster-row, 1819, p. 397. No original: "the history of (...) manners and fortunes", "of all books relating to savage life the most curious, and in every respect the most interesting".

3 SOUTHEY, Robert. An account of the Abipones, an equestrian people of Paraguay. Quarterly Review, vol. 26, n. 52, 1822, p. 292, grifos meus. No original: "There are no parts of history more interesting than those which relate to the transitions from one stage of society to another. When nations are progressive, every step of the progress has some advantages - some virtues peculiar to itself; something which, while it delights us, excites something like regret that it should have passed away. (...) But in that part of South America of which we are now treating, the transitions were not for the better: among the Indians, the change was from one mode of savage life to another; among the Spaniards, from a bold and adventurous to a stagnant brutality". 
A proposta deste artigo é analisar como a articulação da teoria dos quatro estágios serviu de pano de fundo em History of Brazil (1810-1819), escrita por Robert Southey, para o exame das populações originárias que viviam no Brasil, Rio da Prata e Paraguai. A teoria dos quatro estágios, forjada no século XVIII, pode ser entendida como uma das respostas ao interesse setecentista pelo social e sentimental. Esse interesse gerou duas formas narrativas que, juntas, buscavam investigar os aspectos da vida social de forma abrangente. Esse desafio de narrar tanto as maneiras dos povos como a sua interioridade foi parte crucial de uma ampla investigação da Ilustração escocesa sobre a natureza e a experiência humanas. ${ }^{4}$ Em sintonia com essa proposta de investigação do social, a teoria dos estágios civilizacionais difundiu um padrão de desenvolvimento da história do ser humano que permitia ao historiador delimitar o estágio em que as sociedades se encontravam por meio da descoberta de seu modo de subsistência, que mudava de acordo com o crescimento populacional ou o esgotamento dos recursos naturais. Criou-se, assim, uma teoria do progresso social em que a caça e a coleta de vegetais foram substituídas pelo pastoreio, que, por sua vez, foi sucedido pela agricultura. O último estágio foi definido como o comercial, em que o progresso da opulência trouxe consigo o refinamento das maneiras e uma sociedade civilizada. Esse plano explicativo, resultado de um grande interesse pela esfera social e pela etnografia, foi concebido como uma tentativa de elucidar a questão de como algumas sociedades tinham atingido a civilização, enquanto outras definhavam na barbárie ou mesmo na selvageria. ${ }^{5}$

Enquanto delimitar se determinada sociedade estava baseada na caça, pastoreio, agricultura ou comércio dizia sobre seu desenvolvimento econômico e seu modo de subsistência, identificá-la como selvagem, bárbara ou polida enfatizava o seu progresso moral. ${ }^{6}$ Nesse horizonte de delimitação das sociedades em bárbaras, selvagens ou civilizadas, History of America (1777) de William Robertson (1721-1793) foi decisiva para a construção dos povos indígenas americanos como vivendo em um estado selvagem. ${ }^{7}$ A abordagem

\footnotetext{
${ }^{4}$ PHILLIPS, Mark Salber. Society and sentiment: genres of historical writing in Britain 1740-1820. Princeton: Princeton University Press, 2000a, p. 87.

5 CRAIG, David M. Robert Southey and romantic apostasy: political argument in Britain 1780-1840. Royal Historical Society: Boydell Press, 2007, p. 142-143.

${ }^{6}$ MACLEOD, Emma. Revolution. In: GARRETT, Aaron \& HARRIS, James A. Scottish philosophy in the eighteenth century: morals, politics, art, religion. Oxford: Oxford University Press, 2015, p. 364.

7 POCOCK, J. G. A. Barbarism and religion: barbarians, savages and empires, vol. 4. Cambridge: Cambridge University Press, 2005, p. 186.
} 
sociológica e etnográfica, baseada na descrição do modo de subsistência e de como esse afetava os costumes e maneiras dos povos, passou a ser prescritiva para explicar o estado da população não apenas da Europa, mas também do Novo Mundo. Southey continuou explorando as maneiras e os costumes dos selvagens, realizando um significativo alargamento dos tópicos e esmiuçando as peculiaridades de diversas tribos sem, contudo, deixar de apontar seus modos de subsistência, que se desenvolviam de acordo com estágios previamente delimitados.

Robertson foi um dos historiadores mais respeitados do século XVIII, clérigo da Igreja da Escócia, reitor da Universidade de Edimburgo e historiógrafo real da Escócia. ${ }^{8}$ Compartilhava da tradição calvinista historiográfica ancorada em uma teologia providencialista.? Acreditava que era parte do plano divino de expansão do cristianismo e, consequentemente, do progresso da sociedade conceder a uma civilização superior o poder de unificar e civilizar o mundo. ${ }^{10}$ Tanto em suas polêmicas relacionadas à Igreja quanto à escrita da história encorajava uma visão mais tolerante e aberta do desenvolvimento cultural. ${ }^{11}$ Isso o levou a afirmar, em sua History of America, que escreveria sobre os povos americanos sem as marcas do preconceito de seus predecessores laicos e sem as de santificação dos católicos. ${ }^{12}$

Robertson escreveu três histórias que, de forma geral, debruçaram-se sobre características institucionais e culturais das nações no intuito de situá-las em estruturas narrativas amplas. Na The history of the reign of Charles $V$ (1769), publicada em quatro volumes, buscava justamente elucidar como os povos europeus, no século XVI, foram conduzidos à civilização prescrita pela providência divina. O livro é uma investigação sociológica do processo de aperfeiçoamento europeu e tenta chegar a formulações gerais sobre as causas das mudanças sociais ocorridas. ${ }^{13}$ Em sua History of Scotland (1759), em dois volumes, com a impressionante marca de catorze edições em apenas três dé-

\footnotetext{
${ }^{8}$ Para uma explicação das características e da história desse cargo, ver HAY, Denys. The historiographers royal in England and Scotland. Scottish Historical Review, vol. 30, 1951, p. 15-29.

9 ALLAN apud BROWN, Stewart J. William Robertson (1721-1793) and the Scottish Enlightenment. In: Idem (ed.). William Robertson and the expansion of Empire. Cambridge: Cambridge University Press, 2008, p. 19.

${ }^{10}$ SEBASTIANI, Silvia. The Scottish Enlightenment: race, gender, and the limits of progress. Palgrave, 2013, p. 93.

${ }^{11}$ BROWN, Stewart J., op. cit., 2008, p. 7.

${ }^{12}$ ROBERTSON, William. Book IV. In: Idem. The history of America, vol. I. Dublin: Whitestone etc., 1777, p. 284-286.

${ }^{13}$ O'BRIEN, Karen. Narratives of Enlightenment: cosmopolitan history from Voltaire to Gibbon. Cambridge: Cambridge University Press, 2005, p. 130-131.
} 
cadas, ${ }^{14}$ era clara sua concepção de história acumulativa, mas ainda não estava em plena sintonia com o vocabulário do modo de subsistência, tão importante para a teoria dos estágios civilizacionais. ${ }^{15}$ Não parece uma simples coincidência que isso tenha sido feito apenas em History of America, sua última história a ser publicada. A seu ver, a validade da história local ou nacional relacionava-se com a sua possibilidade de inserção na história universal. ${ }^{16}$ Nesse sentido, seu interesse pela história da América pode ser entendido dentro de um horizonte europeu de referência em que o local só era relevante quando considerado como integrante desse grande quadro universal. ${ }^{17}$

History of America, como suas obras anteriores, teve grande sucesso entre seus contemporâneos, com seis edições no intervalo de dezesseis anos. Nela Robertson buscou, sobretudo, realizar a fusão entre a grande narrativa cosmopolita, em que situava uma história particular dentro de uma perspectiva universal, e a pesquisa sociológica. ${ }^{18} \mathrm{O}$ plano inicial de Robertson era escrever a história das três Américas, mas com o alvorecer do movimento de independência estadunidense, acabou reconfigurando o projeto e deixando a conclusão dessa parte, já iniciada, para uma ocasião mais apropriada. Grande parte dos três volumes, contudo, é dedicada à análise da colonização espanhola, principalmente no México, Peru e Caribe, sob a justificativa do modelo de colonização espanhol ter servido como parâmetro para as demais iniciativas expansionistas. A América portuguesa e os assentamentos de diversas nações europeias nas ilhas das Índias Ocidentais também foram deixados em aberto por Robertson, que, no prefácio, comprometia-se a aborda-los futuramente. ${ }^{19}$

Nesse sentido, busco mostrar a importância de History of America de William Robertson para a inserção da história americana dentro da macronarrativa da história universal através da circunscrição dos povos originários como moralmente selvagens e vivendo no estágio de caçadores e coletores. ${ }^{20}$ Robertson dedicou-se a escrita da história da América que havia sido

\footnotetext{
${ }^{14}$ O'BRIEN, Karen, op. cit., 2005, p. 97.

15 O'BRIEN, Karen, op. cit., 2005, p. 101.

${ }^{16}$ O'BRIEN, Karen, op. cit., 2005, p. 98-100.

${ }^{17}$ O'BRIEN, Karen, op. cit., 2005, p. 94.

${ }^{18}$ O'BRIEN, Karen, op. cit., 2005, p. 130-131.

${ }^{19}$ ROBERTSON, William. Preface. In: Idem. The history of America, vol. I. $4^{\mathrm{a}}$ edição. Londres: Strahan; Cadell, 1783a, p. V-VI.

${ }^{20}$ Não obstante nenhum historiador antes de Southey ter utilizado a teoria dos quatro estágios para narrar a história brasileira enquanto uma macronarrativa separada da história de Portugal, em uma obra do gênero história, ele não foi o primeiro a recorrer a Robertson para
} 
colonizada pelos espanhóis e pelos britânicos (Estados Unidos), mas dentro dessa grande América ainda faltava ser contada a história dos selvagens brasileiros "descobertos" com a colonização portuguesa. Tal tarefa foi assumida por Southey, que reconhecia a diversidade dos estágios civilizacionais que existiam sincronicamente em solo brasileiro tanto no que dizia respeito ao modo de subsistência quanto ao estado moral. Southey estava longe de ser um entusiasta das obras de Robertson, mas nem por isso deixou de ser devedor da interpretação sobre a história americana proposta por ele. ${ }^{21}$

Ao longo da vida, Southey teve os mais vastos interesses literários, escreveu várias obras poéticas e três histórias, além de diversos ensaios publicados em periódicos ingleses e obras de outros gêneros. Começou na vida literária como poeta, mas durante os anos de 1800 definia-se mais como um historiador. ${ }^{22}$ History of Brazil existiu inicialmente enquanto parte do ambicioso projeto de escrita de uma história do Império português, que sofreu diversas reformulações desde a sua primeira concepção em 1800, quando Southey realizou sua segunda viagem a Portugal. ${ }^{23}$ Dentro desse projeto, caberiam volumes sobre a história de Portugal, do Império português na Ásia, da literatura espanhola e portuguesa, do Brasil, dos jesuítas no Japão, das ordens monásticas e das possessões africanas. ${ }^{24}$

O papel do tio de Southey, o reverendo Herbert Hill, a quem sua History of Brazil foi dedicada, parece ter sido crucial tanto para o desenvolvimento do interesse de Southey por Portugal quanto pelo Brasil. Hill, um grande colecionador de documentos sobre o Império português, morou em Sintra durante muitos anos e atuava como capelão em Lisboa, exercendo ativida-

analisar os ameríndios. Vide, por exemplo, o caso de Alexandre Rodrigues Ferreira (1756-1815): RAMINELLII, Ronald \& SILVA, Bruno da. Teorias e imagens antropológicas na Viagem filosófica de Alexandre Rodrigues Ferreira (1783-1792). Bol. Mus. para. Emílio Goeldi. Cienc. Hum., vol. 9, n. 2, Belém, maio-ago 2014, p. 323-342.

${ }^{21}$ A aproximação entre Southey e Robertson não é fortuita. Para uma explicação mais detalhada sobre as leituras de Southey das obras históricas de Robertson, vide: VARELLA, Flávia Florentino. Reunindo o passado: contextos discursivos e linguagens historiográficas na History of Brazil de Robert Southey. Tese de doutorado em História, Instituto de Filosofia e Ciências Humanas, Universidade Federal do Rio Grande do Sul, Porto Alegre, 2015, p. 151-155.

22 STOREY, Mark. "Bob Southey! - Poet Laureate": public and private in Southey's poems of 1816. In: PRATT, Lynda (ed.). Robert Southey and the contexts of English romanticism. Farnham: Ashgate, 2006, p. 91.

${ }^{23}$ HUMPHREYS, R. A. Robert Southey and his History of Brazil. Londres: Hispanic and Luso-Brazilian Council, 1978, p. 6.

${ }^{24}$ SOUTHEY, Charles Cuthbert (ed.). Life and correspondence of Robert Southey. Nova York: Harper $\mathcal{E}^{*}$ Brothers, 1855, p. 183. Carta a Thomas Southey, Keswick, 12 de setembro de 1804. 
des religiosas entre o grupo de agentes comerciais britânicos ou negociantes residentes na cidade. ${ }^{25}$ History of Brazil foi escrita tendo como base esses materiais reunidos por Herbert Hill, além de outros que Southey conseguiu por intermédio de diversas pessoas. A prioridade na escrita dessa história em relação às demais também ocorreu graças à interferência direta de Hill. O plano inicial de Southey previa que a história do Império português começasse com a história de Portugal, sendo que a do Brasil não tinha centralidade nenhuma. Contudo, em finais de 1806, o projeto de escrita da história brasileira ganhou prioridade de composição. A perspectiva de remoção da família real e as constantes perguntas feitas sobre o Brasil em Lisboa impulsionaram Hill a por à disposição de Southey materiais inéditos que havia recolhido ao longo de quase 25 anos. Hill acreditava que Southey poderia escrever a história do Brasil e, assim como o governo inglês necessitava ser notificado, provavelmente pensava que este poderia servir de patrocinador do trabalho de seu sobrinho. Contudo, lorde Grenville, então primeiro-ministro do Reino Unido, não tinha interesse imediato nas informações sobre o Brasil, alegando que lhe interessava mais a outra parte da América do Sul. Os documentos que chegaram até Southey por intermédio de seu tio diziam respeito ao estado do interior do Brasil, mostrando todos os detalhes sobre as minas auríferas brasileiras e pondo em evidência a necessidade de colocá-las fora do alcance do poderio francês. ${ }^{26}$

Assim, de todos os volumes pensados para compor a história do Império português apenas History of Brazil foi escrita e impressa, existindo, em manuscrito não finalizado, a History of Portugal. ${ }^{27}$ É claro, portanto, que Southey, em um primeiro momento, não nutria nenhum interesse particular sobre o Brasil e encarava sua história como intrinsecamente relacionada a uma história mais abrangente do Império português. Southey tinha um interesse

\footnotetext{
${ }^{25}$ CURRY, Kenneth. Southey. Londres: Routledge, 1975, p. 33.

${ }^{26}$ Carta a Charles Watkin Williams Wynn, 15 de dezembro de 1806. Disponível em: www.rc.umd. edu/editions/southey_letters/Part_Three/HTML/letterEEd.26.1243.html\#2. Carta a Charles Danvers, 28 de dezembro de 1806. Disponível em: www.rc.umd.edu/editions/southey_letters/ Part_Three/HTML/letterEEd.26.1250.html\#back2. Carta a John May, 29 de dezembro de 1806. Disponível em: www.rc.umd.edu/editions/southey_letters/Part_Three/HTML/letterEEd.26.1252. html\#3. Carta à Mary Barker, 4 de fevereiro de 1807. Disponível em: www.rc.umd.edu/editions/ southey_letters/Part_Three/HTML/letterEEd.26.1273.html. Acessos em: 20 out. 2016.

${ }^{27}$ PINTO, Alexandre Dias. The elusive manuscript of Robert Southey's History of Portugal. In: XXVII ENCONTRO DA APEAA. Novos Caminhos da História e da Cultura - Actas. Carcavelos, abril 2006. Lisboa: Apeaa $\mathcal{E}$ Ceap, Faculdade de Ciências Sociais e Humanas, 2007.
} 
profundo na missão civilizacional para um mundo não civilizado e em tudo que dizia respeito à carência de civilização encontrada em alguns povos. ${ }^{28}$

History of Brazil não chegou nem perto do sucesso de vendas que foi History of America de Robertson, um clássico desde o seu lançamento. Para se ter uma noção em relação ao interesse despertado no público leitor pelo tema e pela forma de escrita de ambos os autores, a história de Southey contou com uma tiragem de 750 exemplares por volume. ${ }^{29}$ Em 1822, houve uma reimpressão revista do primeiro volume para dar vazão às 170 cópias encalhadas, em 1820, dos segundo e terceiro volumes. ${ }^{30}$ A primeira edição de History of America, por outro lado, vendeu 3 mil cópias, quantidade para a época considerada bastante expressiva e que ajudou a consolidar o nome de Robertson como uma referência no que dizia respeito à história do continente americano. ${ }^{31}$

Em sintonia com o revisionismo em relação ao Romantismo, encontrase também a reformulação da relação existente entre os literatos do início do século XIX, os ditos românticos, e seus antecessores imediatos. Os escritores de início do século XIX certamente não realizaram um movimento conscientemente oposto às formas de expressão da Ilustração. ${ }^{32}$ A comparação dicotômica entre Romantismo e Ilustração - ou Iluminismo - levou ao entendimento do Romantismo como um novo espírito de época, fundamentalmente reacionário, que surgia como resposta à excessiva racionalidade ilustrada. ${ }^{33}$ Esse entendimento de saturação epistêmica pautou grande parte das discussões sobre o Romantismo, que focaram principalmente em argumentos psicológicos, do gênio e da imaginação, que seriam mais importantes

\footnotetext{
${ }^{28}$ CRAIG, David M., op. cit., 2007.

${ }^{29}$ ST CLAIR, William. The reading nation in the romantic period. Cambridge: Cambridge University Press, 2007, p. 218, 555 e 557.

${ }^{30}$ WARTER, John Wood (ed.). Selections from the letters of Robert Southey, vol. 3. Londres: Longman, Brown, Green and Longmans, 1856a, p. 181; WARTER, John Wood (ed.). Selections from the letters of Robert Southey, vol. 4. Londres: Longman, Brown, Green and Longmans, 1856b, p. 301. Carta ao reverendo Herbert Hill, Keswick, 18 de fevereiro de 1820 e carta ao sr. Bray, Tavistock, Keswick, 8 de setembro de 1832.

${ }^{31}$ SHER, Richard B. The Enlightenment and the book. Chicago: Chicago University Press, 2006, p. 87.

${ }^{32}$ BROWN, Marshall. Romanticism and Enlightenment. In: CURRAN, Stuart (ed.). The Cambridge companion to British romanticism. $2^{\mathrm{a}}$ edição. Cambridge: Cambridge University Press, 2010, p. 35.

33 Para o caso específico de Southey ver DIAS, Maria Odila da Silva. O fardo do homem branco: Southey, historiador do Brasil. São Paulo: Companhia Editora Nacional, 1974, p. 68 e p. 74, em que afirma: "também se opunham [Southey e os 'lakistas'] à história conjectural e generalizadora do século XVIII", "A preocupação com o pormenor concreto e visual, com a história factual, era pois uma reação contra as generalizações da Ilustração".
} 
para o entendimento de uma época classicamente aclamada como a era do lirismo e da criatividade autoral. ${ }^{34}$

Conquanto, não parece ter existido uma ruptura completa entre as questões, debates e interpretações forjadas principalmente na segunda metade do século XVIII e o que foi escrito nas primeiras décadas do século seguinte. ${ }^{35}$ Como fica claro a partir de uma apreciação de History of Brazil, existiam elementos importantes de continuidade entre Southey e Robertson no que dizia respeito à análise da sociedade colonial ibérica, via teoria dos quatro estágios civilizacionais, e à caracterização negativa da experiência colonizadora, principalmente no que dizia respeito à espanhola. ${ }^{36}$

A teoria dos quatro estágios civilizacionais foi um dos produtos gerados a partir da tomada de consciência de que existiria um processo histórico global com regularidades. Esse esquema interpretativo sofreu lances que mudaram alguns de seus componentes. Isso significa dizer que a teoria dos estágios civilizacionais à disposição de Southey não era a mesma empregada por Robertson. Porém, é possível perceber que esse era um horizonte importante na medida em que existem trechos em que Southey usa claramente o vocabulário dos modos de subsistência. São inúmeros os exemplos nesse sentido, como a afirmação de que sete freguesias próximas ao rio Quecuéné eram "habitadas principalmente ou exclusivamente por índios no primeiro estágio de civilização" tribos de "caçadores e pescadores" (hunters and fishers). ${ }^{38} \mathrm{Na}$ expedição pelo rio Pilcomayo, após verificarem que não existia profundidade suficiente para continuar a navegação,

\footnotetext{
${ }^{34}$ SISKIN, Clifford. The problem of periodization: Enlightenment, romanticism and the fate of system. In: CHANDLER, James (ed.). The Cambridge history of English romantic literature. Cambridge: Cambridge University Press, 2012, p. 101 e 114.

35 BROWN, Marshall, op. cit., 2010, p. 35-37.

${ }^{36}$ Essa mesma teoria também foi objeto de grandes discussões no cenário francês, mas, como ficará mais evidente no decorrer da minha argumentação, o debate travado na Escócia parece ser mais importante para entender o horizonte de escrita de Southey. Para o caso francês, ver MEEK, Ronald. Social science and the ignoble savage. Cambridge: Cambridge University Press, 2010, p. 68-98.

37 SOUTHEY, Robert, op. cit., 1819, p. 716, grifos meus. No original: "inhabited chiefly or wholly by Indians in the first stage of civilization".

${ }^{38}$ SOUTHEY, Robert. History of Brazil, vol. I. Londres: Longman, Hurst, Rees, and Orme, Paternoster-row, 1810, p. 39, 67, 123.
} 
Patino e Niebla, portanto, procederam com parte dos companheiros nos barcos; e, de acordo com seus cálculos, subiram mais de mil quilômetros adiante até que chegaram a uma tribo avançada consideravelmente em relação ao estado selvagem. Eles eram agricultores; eles criavam ovelhas e faziam um bom pano de lã e eles tinham cavalos em grande número. ${ }^{39}$

Entrelaçado ao modo de subsistência estava também o vocabulário relacionado à vida selvagem. A delimitação do horizonte semântico realizada por Robertson em que as tribos indígenas, de forma geral, eram entendidas enquanto selvagens - e não mais como simplesmente bárbaras - foi decisiva para mapear o progresso moral da América. Esses movimentos historiográficos iniciais foram cruciais para a cristalização da abordagem das populações nativas enquanto selvagens e em um estado social primevo quando da chegada dos europeus na América.

\section{Bárbaros ou selvagens?}

Pode-se considerar que existiram diversas antecipações da teoria dos quatro estágios civilizacionais, que vão desde Dicearco de Messina até Hugo Grotius, mas nenhuma delas colocou o modo de subsistência como fator basilar para o desenvolvimento da sociedade civil e de seus costumes e suas maneiras. A característica fundamental da teoria dos estágios civilizacionais é, portanto, a ligação direta entre o modo de subsistência e o estágio civilizacional de uma sociedade. As investigações sobre a origem da propriedade, a história providencialista e a querela entre antigos e modernos foram debates particularmente importantes para a formação da teoria dos quatro estágios na segunda metade do século XVIII. ${ }^{40}$ A descrição realizada da população originária americana como selvagem e como um exemplo do estado de natureza foi uma das contribuições mais importantes para o desenvolvimento da teoria dos quatro estágios, pois permitiu o entendimento de que o estado de natureza não era estático, mas estava em movimento, e que os homens foram, antes de tudo, caçadores e coletores. ${ }^{41} \mathrm{O}$ providencialismo divino foi igualmente relevante ao postular que Deus, mesmo obtendo o poder sobre

\footnotetext{
39 SOUTHEY, Robert, op. cit., 1819, p. 197, grifos meus. No original: "Patino and Niebla therefore proceeded with part of the company in the boats; and according to their computation, ascended more than a thousand miles further, till they came to a tribe considerably advanced beyond the savage state. They were agriculturists; they reared sheep and made a good cloth of the wool, and they had horses in great numbers".

${ }^{40}$ MEEK, Ronald, op. cit., 2010, p. 26.

${ }^{41}$ MEEK, Ronald, op. cit, 2010, p. 9-16.
} 
a história, não poderia interferir constantemente no mundo dos homens por meio de fenômenos sobrenaturais e intervenções diretas. Nesse sentido, restava ao historiador procurar pelas causas remotas a fim de descobrir as disposições divinas secretas. ${ }^{42}$ Aliado a isso, o embate entre antigos e modernos contribuiu para a formação da teoria dos estágios civilizacionais ao questionar a superioridade dos clássicos greco-romanos no que dizia respeito a literatura, filosofia, artes e ciências contemporâneas. Esse questionamento conduziu à naturalização do entendimento do presente como superior e, consequentemente, mais civilizado que o passado ${ }^{43}$ e contribuiu para a tomada de consciência da historiografia das diferentes fases em que a história europeia havia passado desde a Antiguidade clássica. Começou-se, assim, a traçar as mudanças sistêmicas da civilização. ${ }^{44}$

A história do Brasil, como grande parte da história do Novo Mundo, não se enquadrava no modelo narrativo disponibilizado pela historiografia europeia para a explicação do desenvolvimento do homem na Terra, pois trazia à tona um estado social nunca antes registrado. A história dos selvagens deveria ser escrita sob diferentes princípios daqueles da história do homem civilizado tendo em vista que, apesar de viverem predominantemente como caçadores e coletores, tinham em seus costumes e maneiras marcas de uma barbárie tão grande que só poderia ser chamada de selvageria. ${ }^{45}$ Existia uma diferença importante entre selvagens e bárbaros, em que os últimos foram classicamente definidos como aqueles que estavam fora da fronteira de determinado império. Um povo também poderia ser considerado bárbaro se tivesse sido governado por reis como se fosse escravo - como era o caso dos persas - ou se tivesse vivido em vilas e acampamentos na floresta ou em lugares descampados - como os alemães e godos. ${ }^{46}$ Existia, portanto, uma variedade semântica bastante ampla para bárbaro, ampliada ainda mais com o passar dos séculos e o alargamento dos contextos em que era mobilizada. Enquanto a história dos bárbaros está ligada a Heródoto e à tradição greco-

${ }^{42}$ MEEK, Ronald, op. cit., 2010, p. 23-24.

${ }^{43}$ MEEK, Ronald, op. cit., 2010, p. 26.

${ }^{44}$ POCOCK, J. G. A. Barbarism and religion: narratives of civil government, vol. II. Cambridge: Cambridge University Press, 2001, p. 10.

${ }^{45}$ A. P. Leme Lopes apresenta um excelente panorama sobre o surgimento da história natural da humanidade, cf. LOPES, A. P. Leme. Da progressão dos costumes à história natural da humanidade: reflexões escocesas sobre a temporalidade histórica. História da Historiografia, n. 6, 2011, p. 158-170.

${ }^{46}$ POCOCK, J. G. A. Barbarism and religion: barbarians, savages and empires, vol. 4. Cambridge: Cambridge University Press, 2005, p. 11-12. 
-romana, que passa pela Germânia de Tácito, em que os povos não falantes do grego ou, posteriormente, do latim eram enquadrados como bárbaros, a história dos selvagens se mostrou como um fértil campo investigativo com a descoberta do Novo Mundo. Durante o século XVIII, os selvagens do Novo Mundo foram incluídos na história filosófica ao integrarem a narrativa do desenvolvimento da sociedade civil e de seus costumes e maneiras. ${ }^{47}$

Barbarismo e selvageria foram igualmente associados aos homens que ainda não tinham alcançado ou talvez fossem incapazes de alcançar o objetivo natural da vida de viver em cidades e dispor de virtudes políticas e sociais enquanto pré-condições para se autogovernarem e governarem os outros. ${ }^{48}$ Selvagem é um termo neolatino significativamente mais recente do que bárbaro, embora tenha existido dentro da mitologia grega para caracterizar humanos primitivos ou pré-sociais. Os ciclopes ou titãs eram selvagens, pois vagavam em pequenos grupos e não tinham os atributos de sociabilidade, incluindo lei e sistema de governo, encarados como sinais de humanidade. Sociabilidade foi tão longamente identificada com humanidade que o termo selvagem esteve constantemente associado às práticas contrárias a natureza, tais como canibalismo, incesto e sodomia. ${ }^{49}$

Após a descoberta do Novo Mundo e da certeza de que os seus habitantes eram seres humanos e não monstros, houve a necessidade de integrá-los à história sacra e à filosofia aristotélica da natureza..$^{50} \mathrm{O}$ Novo Mundo exigia uma nova história, em um sentido filosófico e narrativo, e a historiografia foi pressionada por essa nova demanda. ${ }^{51}$ Os americanos, de forma geral, viviam em pequenas sociedades de caçadores e coletores onde não existia uma estrutura de governo nem o manejo do cavalo, do aço ou da pólvora, que tornavam os europeus habilitados para atuar na história. Tendo em vista o não cumprimento desses e de outros requisitos, não foi muito difícil caracterizar os americanos como selvagens. O selvagem não possuía nenhum dos atributos civilizacionais mais simples - como o arado - e nem existiam indícios de que iria desenvolvê-los. Puxado por bois e cavalos, o arado era visto pelos europeus como condição essencial para o aumento

\footnotetext{
${ }^{47}$ POCOCK, J. G. A, op. cit., 2005, p. 157-158.

${ }^{48}$ POCOCK, J. G. A, op. cit., 2005, p. 158.

${ }^{49}$ POCOCK, J. G. A, op. cit., 2005, p. 159.

${ }^{50}$ Para um aprofundamento de como se deu o processo de reconhecimento dos indígenas como povos que faziam parte do mesmo sistema de desenvolvimento social que os europeus, ver em especial o capítulo "In the beginning all the world was America", em MEEK, Ronald, op. cit., 2010, p. 37-67.

${ }^{51}$ POCOCK, J. G. A, op. cit., 2005, p. 161.
} 
da produtividade da terra e, consequentemente, do excedente de produção, além de servir como instrumento para marcar o limite entre um vizinho e outro, criando uma propriedade visível e definida. ${ }^{52} \mathrm{O}$ entendimento de que não existia o conceito de propriedade na cultura indígena facilitou a legitimação da colonização da América por parte de seus conquistadores. Como o indígena não era proprietário da terra em que vivia, poderia ser conduzido a outro local mais apropriado ao colonizador. Por estarem em um estágio anterior ao agrícola, não tinham desenvolvido a ideia de propriedade.

Apesar do conceito de selvagem constituir de forma decisiva a filosofia do progresso da sociedade, existente na teoria dos quatro estágios, esse estado moral da sociedade não fazia parte da narrativa da história europeia. A história do Velho Mundo começava com os bárbaros pastores e a condição de selvagem vinha antes disso. ${ }^{53}$ Não existiria uma fase desse tipo para ser narrada na história europeia. Enquanto o estado selvagem foi expulso dessa história, o progresso da sociedade foi expulso da história da América pré-colombiana. Havia um consenso formulado de que a passagem de uma sociedade de caçadores para uma de pastores, para uma de agricultores e depois para uma de comerciantes e cidadãos polidos - movimento que constituía o progresso da sociedade em si - tinha ocorrido apenas na Europa. ${ }^{54}$ Esse horizonte discursivo foi importante para a formulação da macronarrativa nacional brasileira na medida em que propiciou a escrita de uma história de luta não apenas da civilização contra o barbarismo, mas também contra a selvageria. Southey tinha consciência da diferença entre os estágios bárbaro e selvagem na medida em que, de forma geral, apontava que os indígenas brasileiros viviam em um estado selvagem e os demais habitantes ainda em uma sociedade cristã bárbara envolta em superstições e fábulas. ${ }^{55}$

\section{A teoria dos estágios civilizacionais e History of America de William Robertson}

A ampliação nos gêneros históricos ocorrida no século XVIII no que se refere ao interesse por um discurso sobre o social, que abarcaria tanto o jogo

\footnotetext{
${ }^{52}$ POCOCK, J. G. A, op. cit., 2005, p. 173.

53 POCOCK, J. G. A, op. cit., 2005, p. 187.

${ }^{54}$ POCOCK, J. G. A, op. cit., 2001, p. 328.

55 SOUTHEY, Robert. History of Brazil, vol. II. Londres: Longman, Hurst, Rees, and Orme, Paternoster-row, 1817, p. 380.
} 
das paixões e sentimentos na mente de cada indivíduo quanto as dimensões materiais da vida da humanidade, é um horizonte que não podemos descartar para entender a variedade do gênero história. Os historiadores, de forma geral, tiveram que enfrentar significativos desafios advindos da ampliação do objeto histórico que, além da tradicional representação da ação por meio da história política, poderia, e muitas vezes deveria, abarcar a experiência das mulheres, das nações ditas rudes, das artes, da história da literatura etc. ${ }^{56}$ É sintomático desse novo interesse pelo social que o termo civilização tenha surgido em meados do século XVIII, sincronicamente na França e na Escócia, ao mesmo tempo em que os letrados setecentistas buscavam investigar os múltiplos aspectos do viver em sociedade. Civilização foi então definida como o caráter geral de uma sociedade e ajudou a articular e definir a oposição entre os pares civilização-barbárie e civilização-selvageria. ${ }^{57}$

Esse novo esquema histórico e sociológico, que se desenvolveu entre 1750 e 1770, contou com um novo método historiográfico baseado em estágios. ${ }^{58}$ Dentro desse cenário, os ameríndios tiveram papel de destaque, pois permitiam aos europeus entrar em uma espécie de máquina do tempo e presenciar uma parte da história que nenhum povo europeu poderia encontrar em suas tradições escritas. Os registros mais antigos que tinham à disposição eram os das sociedades pastoris da Antiguidade europeia, muito posteriores aos caçadores e coletores americanos. ${ }^{59}$ É possível afirmar, portanto, que, em meados do século XVIII, era forte a ligação entre diferenças no comportamento cultural e diferenças nas taxas de desenvolvimento social, abrindo caminho para uma etnologia universal comparada. A diferença cultural entre as diversas sociedades poderia ser explicada por meio da indicação dos estágios em que elas tinham chegado ao longo do tempo. ${ }^{60}$

Na segunda metade do século XVIII, portanto, filósofos e cientistas sociais concluíram que os princípios de sociabilidade respeitados pelos nativos americanos indicavam uma sociedade selvagem, sem demonstrar muito interesse em desenvolver essa apreciação dentro da narrativa das histórias nacionais. William Robertson foi o primeiro a testar e refinar a teoria dos

\footnotetext{
${ }^{56}$ PHILLIPS, Mark Salber, op. cit., 2000, p. 3-30.

57 PIMENTA, Pedro Paulo. Refinamento e civilização: ou como se colocar à altura de seu tempo. In: Idem. A imaginação crítica: Hume no século das luzes. Rio de Janeiro: Beco do Azougue, 2013, p. 123-134.

58 SEBASTIANI, Silvia, op. cit., 2013, p. 73, p. 78.

59 SEBASTIANI, Silvia, op. cit., 2013, p. 92.

${ }^{60}$ PAGDEN, Anthony. The fall of natural man: the American Indian and the origins of comparative ethnology. Cambridge: Cambridge University Press, 1986, p. 2 e 4.
} 
quatro estágios em uma história detalhada da América. ${ }^{61}$ Robertson empregou, de forma inédita, em sua History of America, o vocabulário da teoria dos quatro estágios, salientando a relação direta entre modo de subsistência e estágio civilizacional. Segundo ele, "em todas as investigações relativas às atuações dos homens, quando unidos em sociedade, o primeiro objeto de atenção deve ser o seu modo de subsistência".62 A partir do momento em que Robertson propôs que "entre estas [pequenas tribos independentes], embora com alguma diversidade em seu temperamento, sua maneira e instituições, o estado da sociedade era quase idêntico, e tão extremamente rude, que a denominação de Selvagem pode ser aplicada a todas elas", ${ }^{63}$ os primeiros habitantes do Novo Mundo atenderam definitivamente por selvagens e o termo bárbaro foi reservado, de forma geral, para o rude europeu. ${ }^{64}$ Ao provar que o estágio selvagem havia existido entre os nativos americanos, Robertson abriu um novo horizonte interpretativo sobre o Novo Mundo, que não era mais analisado tendo como contraponto comparativo cidades como a Roma antiga. ${ }^{65}$ Os povos do Novo Mundo só poderiam ser tomados em mesmo grau civilizacional que os europeus na medida em que ganhassem atributos de sociabilidade suficientes para poderem ser chamados, ao menos, de bárbaros.

A teoria dos estágios civilizacionais foi desenvolvida como um sistema de referência histórico a partir do qual seria possível revelar os princípios e perversões subjacentes às regularidades da natureza que operavam a história através de uma análise comparada das diferentes sociedades. Como foi frisado por Robertson, "não é através da teoria ou de conjecturas que a história sentencia no que diz respeito ao estado ou caráter das nações. Ela produz fatos que são a fundação de cada julgamento que venture pronun-

\footnotetext{
${ }^{61}$ PHILLIPSON, Nicolas. Providence and progress: an introduction to the historical thought of William Robertson. In: BROWN, Stewart J. (ed.). William Robertson and the expansion of Empire. Cambridge: Cambridge University Press, 2008, p. 64.

${ }^{62}$ ROBERTSON, William. Book IV. In: Idem. The history of America, vol. II. $4^{\text {a }}$ edição. Londres: Strahan; Cadell, 1783b, p. 95. No original: "in every inquiry concerning the operations of men, when united together in society, the first object of attention should be their mode of subsistence".

${ }^{63}$ ROBERTSON, William, op. cit., 1783b, p. 45-46, grifo no original. No original: "among these [small independent tribes], though with some diversity in their character, their manner and institutions, the state of society was nearly similar, and so extremely rude, that the denomination of Savage may be applied to them all".

${ }^{64}$ POCOCK, J. G. A, op. cit., 2005, p. 186.

${ }^{65}$ CAÑIZARES-ESGUERRA, Jorge. Como escrever a história do Novo Mundo: histórias, epistemologias e identidades no mundo atlântico do século XVIII. São Paulo: Edusp, 2011, p. 62-63.
} 
ciar". ${ }^{66}$ A teoria dos estágios das sociedades não era um modelo pré-fabricado pronto para ser utilizado de forma indiscriminada. ${ }^{67}$ Utilizar-se dos modos de subsistência como base teórica para a explicação do progresso do homem não significava, para os letrados setecentistas, corromper a história, mas produzir macronarrativas através da comparação dos fatos das sociedades particulares. A história desenvolvia-se em estágios capazes de serem mapeados como sistemas organizados e que explicavam o desenvolvimento das sociedades. ${ }^{68}$ Robertson, em History of America, imbuiu essa teoria explicativa de uma forma narrativa ao subscrever que a mudança moral e material é qualitativa e que a Europa possuía inata superioridade cultural, tendo em vista que foi a primeira parte do mundo a chegar à fase comercial. ${ }^{69}$

Os habitantes da América foram essenciais para a construção do método comparativo subjacente a teoria dos estágios, mas também um problema investigativo já que não tinham avançado para além da caça e da coleta. Assim, não obstante completarem o mapa da humanidade, fornecendo materiais que remontavam a uma fase primordial perdida para a memória europeia, sua estagnação era algo que necessitava ser explicado. Ao reafirmar os princípios sociológicos da abordagem em estágios em History of America, Robertson enfatizou as características negativas da permanência no estágio de caçador-coletor. Elementos da teoria da degeneração racial formulada por Cornelius de Pauw (1739-1799) não são incomuns em History of America, corroborando para a catalogação dos indígenas como selvagens e como justificativa para a expansão e a conquista europeia, vistas como os meios pelos quais a providência divina fazia a história humana progredir. ${ }^{70}$

As disputas sobre o Novo Mundo, muito variadas, cristalizaram-se com grande força a partir da Historie naturelle (1749-1789) de Buffon (1707-1788). Houve não apenas um esforço de sistematizar a grande quantidade de material produzido por naturalistas, viajantes e missionários, como foi a partir dessa obra que o debate sobre a inferioridade das Américas começou a ser feito de forma ininterrupta. Antes disso, os relatos anteriores que aborda-

\footnotetext{
${ }^{66}$ ROBERTSON, William. Book VII. In: Idem. The history of America, vol. III. 4 ${ }^{\mathrm{a}}$ edição. Londres: Strahan; Cadell, 1783c, p. 159. No original: "it is not by theory or conjectures that history decides, with regard to the state or character of nations. It produces facts as the foundation of every judgment which it ventures to pronounce".

${ }^{67}$ MEEK, Ronald, op. cit., 2010, p. 239.

${ }^{68}$ O'BRIEN, Karen, op. cit., 2005, p. 133-134.

${ }^{69}$ O'BRIEN, Karen, op. cit., 2005, p. 135-136.

${ }^{70}$ SEBASTIANI, Silvia, op. cit., 2013, p. 74.
} 
ram a natureza americana - como os de Gonzalo Fernández de Oviedo (1478-1557), José de Acosta (1539/40-1600), Antonio de Herrera (1549-1625) e Bernabé Cobo (1582-1657) - não formularam uma teoria geral sobre a inferioridade da natureza americana, nem sobre a imaturidade ou degeneração dos nativos. ${ }^{71}$ A experiência americana, durante o século XVIII, deixou de ser alvo de debate daqueles que tivessem tido uma experiência in loco para espalhar-se como tópico de discussão de todos aqueles que se interessassem pelo desenvolvimento das sociedades, atribuindo uma realidade totalmente nova para a historiografia sobre a América.

O principal interlocutor de Robertson no que diz respeito à tipologia das etapas do avanço social e produtivo das sociedades parece ter sido Adam Smith (1723-1790). ${ }^{72}$ Pensar o desenvolvimento da sociedade através de estágios não era exatamente uma novidade para o período, porém, o mais comum parece ter sido a formulação das etapas em três estágios, que diferiria significativamente da abordagem em quatro. ${ }^{73}$ Em seu "Lectures on jurisprudence" (1762-1763), ao referir-se à aquisição da propriedade, Smith postulava a existência de quatro idades, fases ou estágios: a de caçadores, pastores, agricultores e do comércio. As reflexões de Smith advêm de uma abordagem filosófica do problema do desenvolvimento das sociedades, tanto que nas Lectures sua explicação é baseada em uma hipótese teórica fundada na especulação sobre um grupo de pessoas que viveria em uma ilha deserta. A partir dessa especulação, Smith chega à conclusão que o estágio de caçador e coletor seria o primeiro em que os seres humanos poderiam ter vivido já que a primeira forma de subsistência possível ao ser humano deveria ser a coleta de frutas e a caça de animais selvagens. Sucessivos aumentos populacionais fariam com que essa pequena sociedade originária fosse forçada a se organizar de forma distinta para conseguir mais alimento, passando ao estágio pastoril e depois para o agrícola. Neste estágio, a sociedade estava mais desenvolvida, sendo possível que cada um escolhesse tanto o que cultivar quanto o ramo de atividade que preferiria. Assim, graças ao excedente de produção, surge o comércio baseado na troca seja de produtos agrícolas,

\footnotetext{
${ }^{71}$ GERBI, Antonello. O Novo Mundo: história de uma polêmica (1750-1900). São Paulo: Companhia das Letras, 1996, p. 15.

72 VARELLA, Alexandre C. A queda do homem civil: os antigos mexicanos e peruanos na The history of America de William Robertson. História Unisinos, vol. 2, n. 18, maio/agosto 2014, p. 248-259, p. 249.

${ }^{75}$ HONT, Istvan. The language of sociability and commerce: Samuel Pufendorf and the theoretical foundations of the "four-stages theory". In: PAGDEN, Anthony. The languages of political theory in early-modern Europe. Cambridge: Prentice Hall, 1990, p. 253-254.
} 
artesanais ou manufaturados. Essa troca de mercadorias dava-se não apenas entre indivíduos de uma mesma sociedade, mas de outras também, dando origem a expansão do comércio. Para Smith, seria graças à capacidade de produzir excedentes que uma sociedade chegava ao estágio comercial. ${ }^{74}$ Dentro da teoria dos quatro estágios, as pessoas eram forçadas a inventar e inovar para se manterem vivas, caso contrário morreriam de fome ou ficariam eternamente dentro do estágio de caçadores, beneficiando-se exclusivamente dos frutos da natureza. As sociedades passavam de um estágio para o outro graças a uma disfunção, o progresso da sociedade nada mais era do que o resultado de uma adaptação bem sucedida a modos mais antigos, ineficientes e simples de existência. ${ }^{75}$

Na proposta de Smith, a diversidade encontrada nas sociedades mais desenvolvidas era fruto da divisão do trabalho. Junto com a sociedade agrícola teria surgido a propriedade privada que, com a multiplicação das necessidades e profissões, diversificou também as pessoas umas das outras. A diversidade humana era, acima de tudo, um produto da história e poderia ser vista apenas nas sociedades em estágios mais avançados. ${ }^{76}$ A natureza, para Smith, não tinha papel preponderante na construção das diferenças entre os seres humanos, pois essas eram o produto da educação, da hierarquização da sociedade e do sistema econômico. ${ }^{77}$ Os modos de subsistência estariam ligados intrinsecamente aos estágios da sociedade e produziriam respostas diferentes por causa disso. Os caçadores e coletores estariam mais próximos de um estado selvagem, os pastores de uma sociedade bárbara, os agricultores de uma sociedade feudal e, por fim, um sistema envolvendo atividades comerciais complexas de uma sociedade comercial. ${ }^{78}$ Com isso, os caçadores e coletores americanos viveriam em um estágio extremamente menos complexo do que o comercial europeu, facilitando, inclusive, a generalização dos costumes e das maneiras desses povos.

\footnotetext{
${ }^{74}$ SMITH, Adam. The Glasgow edition of the works and correspondence of Adam Smith, vol. V: Lectures on jurisprudence. Editado por R. L. Meek, D. D. Raphael e P. G. Stein. Indianapolis: Liberty Fund, 1978, p. 14-16.

${ }^{75}$ ALLAN, David. Scottish historical writing of the Enlightenment. In: RABASA, José; SATO, Masayuki; TORTAROLO, Edoardo; WOOLF, Daniel (ed.). The Oxford history of historical writing, vol. 3: 1400-1800. Oxford: Oxford University Press, 2012, p. 508.

${ }^{76}$ SEBASTIANI, Silvia, op. cit., 2013, p. 73.

77 SEBASTIANI, Silvia, op. cit., 2013, p. 75

${ }^{78}$ ALLAN, David, op. cit., 2012, p. 508.
} 
Esse tipo de abordagem da sociedade primitiva foi um dos pilares centrais do que poderíamos chamar de história conjectural. Esse gênero de história, além dos elementos constitutivos de uma história filosófica - ampliação dos assuntos para além da política e a descoberta das causas intrínsecas aos fenômenos - tinha como cerne a investigação do início da história do homem. Existe muita divergência no que diz respeito ao que seria a história conjectural, existindo inclusive a proposta de que a teoria dos quatro estágios seria a própria história conjectural. Outra possibilidade também seria entendê-la como sinônimo de história filosófica ou como a investigação especulativa sobre as causas naturais dos eventos que poderiam ter determinado efeito. Em suma, esses termos - filosófica ou conjectural - eram, e continuam sendo, muito disputados. Não obstante essas ressalvas, de um ponto de vista analítico, é bastante profícuo pensar a história conjectural como um gênero distinto da história filosófica, pois evidencia a sua descontinuidade em relação às narrativas clássicas baseadas na ação. A história conjectural seria um dos gêneros que, em termos formais, teve a maior ruptura com a historiográfica de tradição clássica, pois a história não era abordada como uma narrativa política governada por prescrições da retórica clássica, mas como uma ciência moral que investigava os princípios fundamentais da natureza humana. A história conjectural queria explorar a vasta e não documentada experiência humana em qualquer estágio do progresso social. Esse tipo de teoria da história foi crucial para a investigação do progresso da sociedade dentro da história filosófica escocesa na medida em que proporcionou um parâmetro de desenvolvimento das sociedades. ${ }^{79}$

History of America foi a história escrita por Robertson que mais se aproximou das preocupações e métodos da teoria dos estágios civilizacionais escocesa, em particular no que diz respeito aos livros IV e VII. ${ }^{80}$ Como já salientado, Robertson escreveu outros livros de história, mas esse recurso explicativo não foi, em tamanha intensidade, central para contar a história europeia. Em sua opinião, um cenário diferente mostrava-se para a escrita da história americana:

Na América, o homem aparece sob a forma mais rude em que podemos concebê-lo subsistir. Contemplamos comunidades apenas começando a unirem-se e é possível examinar os sentimentos e as ações dos seres humanos na infância da vida social, enquanto

\footnotetext{
79 PHILLIPS, Mark Salber, op. cit., 2000, p. 171.

${ }^{80}$ O'BRIEN, Karen, op. cit., 2005, p. 153.
} 
eles sentem, mas imperfeitamente, a força de seus laços e abandonam raramente sua liberdade nativa. Esse estágio de simplicidade primeva, que era conhecido em nosso continente apenas pela descrição fantasiosa de poetas, realmente existiu no outro. ${ }^{81}$

A descoberta do Novo Mundo permitiu o conhecimento de um estágio da sociedade de que não se tinha relato, pois mesmo o rude alemão ou os citas, descritos pelos romanos, poderiam ser considerados em certo grau de civilização. ${ }^{82}$ É preciso deixar claro, contudo, que Robertson não se refere ao comércio como um estágio do desenvolvimento do homem na Terra e também é verdade que ele estava longe de ser um apóstolo inabalável da doutrina do progresso. Robertson refere-se também, e muitas vezes, aos nativos das Américas utilizando o termo rude e não selvagem. Contudo, existe a ideia explícita em History of America de que os povos que vivem da caça e da pesca - notadamente a maioria dos ameríndios, exceto, em alguma medida, as populações do México e Peru - são os menos civilizados de todos, sendo possível inferir que o estado civilizacional em que o modo de subsistência era baseado na caça e na coleta de vegetais era o mais imperfeito de todos. ${ }^{83}$

No livro IV de History of America, Robertson descreve e explica o nível de desenvolvimento dos povos originários americanos de acordo com a teoria dos quatro estágios. Com exceção dos astecas, maias e incas, as demais populações nativas são exemplos imaculados do estágio de caçador, delimitado pelo seu modo de subsistência. ${ }^{84}$ A maioria das tribos americanas, para Robertson, estava no estágio de caçador-coletor, ocupava partes muito pequenas do território e vivia bastante separada de outras tribos por considerarem inimigo aquele que habitava por perto. Eram rivais na disputa por subsistência. Além disso, acreditavam que deveria existir certa rotatividade em relação ao local em que viviam, contribuindo para o nomadismo. As populações indígenas, apesar de cultivarem a mandioca e outros produtos, não eram predominantemente agrícolas, pois não existia nem a apropriação da terra, nem a ideia de propriedade. ${ }^{85}$ Os agricultores, que faziam da terra sua

\footnotetext{
${ }^{81}$ ROBERTSON, William, op. cit., 1783b, p. 45. No original: "In America, man appears under the rudest form in which we can conceive him to subsist. We behold communities just beginning to unite, and may examine the sentiments and actions of human beings in the infancy of social life, while they feel but imperfectly the force of its ties, and have scarcely relinquished their native liberty. That state of primeval simplicity, which was known in our continent only by the fanciful description of poets, really existed in the other".

${ }^{82}$ ROBERTSON, William, op. cit., 1783b, p. 48.

${ }^{85}$ MEEK, Ronald, op. cit., 2010, p. 143

${ }^{84}$ O'BRIEN, Karen, op. cit., 2005, p. 157.

${ }^{85}$ ROBERTSON, William, op. cit., 1783b, p. 112.
} 
propriedade assim como fonte de produtos, adquiriram diretos e construíram leis para que os caçadores fossem excluídos de uma sociedade fundada na agricultura. ${ }^{86}$ Essa mudança no modo de subsistência não havia ocorrido nas Américas e, "a partir dessa descrição do modo de subsistir entre as rudes tribos americanas, a forma e o gênio de suas instituições políticas podem ser deduzidas, e somos capazes de traçar várias circunstâncias de distinção entre elas e as nações mais civilizadas". ${ }^{87}$ Após History of America, ao menos, a comparação tornou-se um método consolidado de entendimento das tribos indígenas, ou seja, através da descrição e posterior comparação entre os hábitos, instituição etc. dos selvagens e dos civilizados, seria possível ao historiador chegar a conclusões sobre o estado civilizacional do primeiro. Entender o modo de subsistência, com isso, era extremamente importante, pois:

a inclinação e as maneiras dos homens são formadas por sua situação e surgem do estágio da sociedade em que vivem. No momento em que começa a variar, o caráter de um povo deve mudar. Na proporção em que ele avança em direção ao aperfeiçoamento, suas maneiras são refinadas, seus poderes e talentos são convocados. Em cada parte da Terra, o progresso do homem tem sido quase o mesmo e podemos traçar seu curso que vai da rude simplicidade da vida selvagem até quando ele obtém a indústria, as artes e a elegância da sociedade polida. ${ }^{88}$

A abordagem de Robertson pode ser entendida como a combinação de dois discursos sobre o homem primitivo. O primeiro tratava da forma em que o desenvolvimento das sociedades se dava, e foi fornecido pela teoria dos estágios civilizacionais, e o segundo era a tese que afirmava a imaturidade ou degeneração do nativo do Novo Mundo. As avaliações negativas feitas por Robertson sobre os indígenas, advindas da análise do modo de subsistência, são reforçadas pelas suas convicções na imaturidade ou degeneração da América e na superioridade da Europa. ${ }^{89}$

\footnotetext{
${ }^{86}$ POCOCK, J. G. A, op. cit., 2005, p. 168.

${ }^{87}$ ROBERTSON, William, op. cit., 1783b, p. 111. No original: "From this description of the mode of subsisting among the rude American tribes, the form and genius of their political institutions may be deduced, and we are enabled to trace various circumstances of distinction between them and more civilized nations".

${ }^{88}$ ROBERTSON, William, op. cit., 1783b, p. 27. No original: "[...] the disposition and manners of men are formed by their situation, and arise from the state of society in which they live. The moment that begins to vary, the character of a people must change. In proportion as it advances in improvement, their manners refine, their powers and talents are called forth. In every part of the earth the progress of man hath been nearly the same, and we can trace him in his career from the rude simplicity of savage life, until he attains the industry, the arts, and the elegance of polished society".

${ }^{89}$ O'BRIEN, Karen, op. cit., 2005, p. 160.
} 
Em sua procura por padrões comuns e afinidades culturais nas histórias das nações europeias e de suas colônias, Robertson encontrou a mão de Deus organizando a história. ${ }^{90}$ No entanto, o determinismo providencialista contido em History of America levou a uma intensificação do empirismo tendo em vista que a vontade e os propósitos divinos somente poderiam ser revelados através do exame minucioso do tecido causal dos eventos. ${ }^{91} \mathrm{~A}$ história, para Robertson, era acessível à investigação racional porque Deus quase sempre agia através de causas mais ou menos perceptíveis. ${ }^{92}$ Não é de estranhar, portanto, que a identificação das causas dos fenômenos históricos tenha sido sua grande obsessão. Southey também entendia que existia um sistema de leis da natureza e da sociedade, dentro do qual as civilizações nasciam, floresciam e declinavam, identificável mediante observação de certas práticas cotidianas. Em sua opinião, era "pela indústria e empreendimento individual, e pela ação das leis comuns da natureza e da sociedade, que esse império [do Brasil] cresceu e floresceu". ${ }^{93}$ Existiriam, dessa forma, leis externas que orientavam as mudanças ocorridas na sociedade brasileira. Proponho que essas leis estavam intrinsecamente ligadas à teoria dos estágios das sociedades na medida em que essa fornecia o cenário que norteava a classificação das nações dentro dos graus civilizacionais.

\section{A teoria dos estágios civilizacionais e History of Brazil de Robert Southey}

Os bretões não eram selvagens quando os romanos os invadiram e os melhoraram. Eles já estavam muito avançados no estágio bárbaro da sociedade, usando metais, gado doméstico, transporte com rodas e dinheiro; um governo estabelecido e sacerdócio regular estavam conectados com os seus companheiros druidas no continente e não eram ignorantes das letras.94

As palavras de Southey - talvez ecoando a querela entre lord Kames (1696-1782) e Adam Ferguson (1723-1816) sobre se na época da invasão ro-

\footnotetext{
${ }_{90}$ O'BRIEN, Karen, op. cit., 2005, p. 95.

${ }^{91}$ ALLAN apud O'BRIEN, Karen, op. cit., 2005, p. 123.

${ }^{92}$ O'BRIEN, Karen, op. cit., 2005, p. 125.

${ }^{93}$ SOUTHEY, Robert, op. cit., 1810, p. 1, grifos meus. No original: "it is by individual industry and enterprize, and by operation of the common laws of nature and society, that this empire has risen and flourished".

${ }^{94}$ SOUTHEY, Robert. Sir Thomas More: Or Colloquies on the Progress and Prospects of the Society, vol. I. Londres: John Murray, 1829, p. 46, grifos meus. No original: "The Britons were not savages when the Romans invaded and improved them. They were already far advanced in the barbarous stage of society, having
} 
mana os antigos bretões eram ou não muito parecidos com os indígenas americanos $-{ }^{95}$ nos permitem perceber que observar o modo de subsistência e as maneiras dos naturais do Novo Mundo para delimitar o seu estágio dentro do processo civilizatório não era nenhuma novidade no início do século XIX. A teoria dos estágios civilizacionais como contexto linguístico explicativo do desenvolvimento da sociedade estava bastante consolidada, principalmente após Robertson, que afirmava:

O povo de Bogotá subsistia principalmente pela agricultura. A ideia de propriedade foi introduzida entre eles e os seus direitos, garantidos por leis, transmitidos pela tradição e observados com muito cuidado. Eles viviam em grandes cidades. Eles estavam vestidos de forma decente e as suas casas talvez pudessem ser chamadas de cômodas, quando comparadas com as das pequenas tribos entorno deles. ${ }^{96}$

Os nativos que viviam em Bogotá, para Robertson, encontravam-se no estágio de agricultores, conhecendo o conceito de lei e propriedade, mas não apenas isso. Aparecem como indícios de civilização a extensão das comunidades, como se vestiam e o grau de conforto que desfrutavam em suas habitações. A relação entre o modo de subsistência, o estágio civilizacional e as maneiras tornou-se indissociável.

As maneiras dos selvagens eram encaradas por Southey como vestígios que provavam o estado degenerado das tribos ameríndias. Os calchaquis, em sua opinião, eram um exemplo claro de que havia existido uma civilização mais desenvolvida no território americano antes da chegada dos povos europeus. Os domínios da tecelagem, da lã e da manipulação do cobre eram "vestígios de uma civilização da qual tinham degradado". ${ }^{77}$ As descrições feitas por Southey das várias tribos americanas mostram a diversidade desses indícios civilizacionais, que sugeriam o estado mais ou menos desenvolvido de cada tribo dentro de um mesmo estágio de caçadores e coletores. Esses sinais civilizacionais são repetidos ao longo de toda a History of Brazil quando se aborda os nativos americanos.

the use of metals, domestic cattle, wheeled carriages, and money, a settled government, and regular priesthood, who were connected with their fellow Druids on the continent, and who were not ignorant of letters".

95 SEBASTIANI, Silvia, op. cit., 2013, p. 89.

${ }^{96}$ ROBERTSON, William, op. cit., 1783b, p. 123. No original: "The people of Bogota subsisted chiefly by agriculture. The idea of property was introduced among them, and its rights, secured by laws, handed down by tradition, and observed with great care. They lived in large towns. They were clothed in a decent manner, and their houses may be termed commodious, when compared with those of the small tribes around them".

97 SOUTHEY, Robert, op. cit, 1819, p. 395. No original: "vestiges of a civilization from which they had degraded". 
Existia uma grande matização da selvageria, entendida como ausência dos atributos de civilidade. "De todas as tribos brasileiras a mais selvagem e a mais terrível", segundo Southey, vivia nas capitanias de Ilhéus e Porto Seguro e era conhecida pelo nome de aimorés:

não tinham nem roupas nem habitações. Nus como animais, se deitavam como animais nas florestas, $\mathrm{e}$ como animais corriam usando os pés e as mãos por entre sarçais, por onde era impossível segui-los. Durante a estação chuvosa dormiam debaixo de árvores, e tinham destreza suficiente apenas para formar uma cobertura com os ramos. ${ }^{98}$

Faltavam aos aimorés atributos sociais dos mais básicos, como moradia e vestimenta. Sem a primeira era impossível iniciar o processo de socialização das tribos, pois nem sequer possuíam uma organização urbana que pudesse ser chamada de vila. Sociabilidade era sinônimo de civilização e quanto maiores fossem os aparatos de sociabilidade desenvolvidos pelos indígenas, mais fácil poderiam chegar ao estado civilizado. Uma premissa básica para isso era a formação de cidades, organizadas de forma a permitir o contato das pessoas. É constante a referência de Southey à enorme distância que existia entre as tribos que habitavam o Brasil e o Paraguai, realçando a dificuldade de influência e contato pacífico entre os indígenas de forma a cooperarem e desenvolverem hábitos civilizacionais.99 Igualmente "uma causa que retardava o progresso deles era a prática de mudarem frequentemente suas habitações", "não o faziam por que estivesse exausto o solo adjacente, mas pela convicção de que a mudança de residência era essencial à saúde, e pela superstição de que, se abandonassem os hábitos de seus antepassados, seriam destruídos". ${ }^{100}$ De forma inversa, Southey poderia afirmar que "os peruanos e o povo da Nova Espanha não eram selvagens", pois "nenhuma cidade selvagem jamais conteve oito mil casas".101

\footnotetext{
${ }^{98}$ SOUTHEY, Robert, op. cit., 1810, p. 281-282, grifos meus. No original: "of all the Brazilian tribes the most savage, and the most terrible", "They had neither garments nor habitation. Naked as beasts, they laid down like beasts in the woods, and like beasts could run upon hands and feet through thickets, where it was not possible to follow them. During the rainy season they slept under the trees, and had just skill enough to form a roofing with the boughs".

99 SOUTHEY, Robert, op. cit., 1810, p. 164-165.

${ }^{100}$ SOUTHEY, Robert, op. cit., 1810, p. 250, grifos meus. No original: one cause which retarded their improvement was the practice of frequently removing their habitations", "adjoining soil had been exhausted, but from a persuasion that change of abode was essential to health; and a superstition, that if they departed from the custom of their forefathers they should be destroyed".

${ }^{101}$ SOUTHEY, Robert, op. cit., 1810, p. 154-155. No original: "The Peruvians and the people of New Spain were not savages", "no savage town ever contained eight thousand houses".
} 
Os guanás "eram gregários, cada cabana contendo doze famílias, e suas aldeias, que contavam com muitas destas colmeias humanas, eram cercadas de paliçadas com quatro portas que eram regularmente fechadas e vigiadas durante a noite". ${ }^{102}$ Contudo, tornar-se sociável era apenas um dos passos para o viver em sociedade. Os sacocies, xaquesses e chaneses, por exemplo, eram "tribos sociáveis e não gregárias, tendo antes cada família a sua habitação própria. O assentamento tinha por volta de oitocentas".103 A dificuldade de organização dos indígenas para reagir à invasão dos colonizadores espanhóis, para Southey, teria sido fruto da sociedade selvagem em que viviam. ${ }^{104}$ Contudo, quando a vida sedentária era apresentada ao indígena, ele sabia reconhecer as suas vantagens. Foi o que aconteceu com os aimorés que viviam em Itaparica. Após a redução jesuítica em que viviam ser dispersa, alguns deles retornaram para a floresta e para seus parentes: "tais eram os confortos da domesticação que eles frequentemente voltavam, trazendo outros com eles". ${ }^{105}$ Os indígenas, quando experimentavam os confortos da vida civilizada, nesse caso a não nômade, não queriam retornar necessariamente aos hábitos anteriores. O mesmo reconhecimento foi tido pelos aimorés de Ilhéus: "o efeito produzido neles ao ver e experimentar os confortos da vida sedentária foi tão grande quanto os jesuítas haviam esperado: correu a notícia, e logo dois aldeamentos foram formados, um contendo mil e duzentos aimorés e o outro quatrocentos". ${ }^{106}$

Não devemos perder de vista que a importância do vestir-se estava intimamente relacionada com a necessidade de se esconder o corpo nu e torná-lo apto ao convívio social, realçada pelo constante emprego da expressão "decentemente vestidos" (decently clothed) por Southey. ${ }^{107}$ Southey salientava que o missionário jesuíta Cipriano Baraza, quando estava afastado dos moxos, começou "a aprender a tecer, assim ele poderia instruí-los quando

\footnotetext{
${ }^{102}$ SOUTHEY, Robert, op. cit., 1817, p. 374-375, grifos meus. No original: "They were gregarious; every hut contained twelve families; and their villages, which comprised many of these human hives, were palisadoed, having four gates, which were regularly closed and watched at night".

${ }^{103}$ SOUTHEY, Robert, op. cit., 1810, p. 135-136, grifos meus. No original: "were social, not gregarious tribes, each family having its own habitation. The settlement contained about eight hundred".

${ }^{104}$ SOUTHEY, Robert, op. cit., 1822, p. 291.

${ }^{105}$ SOUTHEY, Robert, op. cit., 1810, p. 387, grifos meus. No original: "such were the comforts of domestication, that they frequently returned, bringing others with them".

${ }^{106}$ SOUTHEY, Robert, op. cit., 1810, p. 389, grifos meus. No original: "The effect produced upon them by seeing and experiencing the comforts of settled life was as great as the Jesuits expected: they spread the tidings, and two villages were soon formed, the one containing twelve hundred Aymores, the other four".

${ }^{107}$ Por exemplo: SOUTHEY, Robert, op. cit., 1810, p. 118 e 589.
} 
voltasse numa das primeiras artes da vida civilizada, e induzi-los a vestirem-se como o primeiro passo para a civilização" ${ }^{108}$ Ter uma vestimenta, mesmo que elaborada de forma simples, era indispensável ao convívio social na medida em que escondia o ultrajante corpo nu.

A partir do início do século XVII, iniciou-se um processo de marginalização do corpo dentro da cultura ocidental ao reprimir-se fortemente, por exemplo, a exposição pública das funções naturais, como o escarro e a defecação, e o apresentar-se nu diante de outra pessoa, tidas como indesejáveis socialmente. A apresentação e gestão do corpo estavam, cada vez mais, sujeitas a regras e rituais mais rígidos em que mesmo no deitar-se para dormir era esperado que a pessoa permanecesse vestida. ${ }^{109} \mathrm{O}$ selvagem apresentava ao europeu o inverso dessa imagem ideal do corpo, quando exibia seus apetites e desejos e mostrava seus órgãos genitais sem nenhum pudor.

É possível encontrar a teoria dos estágios civilizacionais guiando o levantamento dos costumes e maneiras que serão apresentados ao leitor de History of America ou de History of Brazil, porém é notável a existência de diferentes níveis de detalhamento quando se contemplam ambas as histórias. Explorando um dos tópicos de grande curiosidade na época sobre os indígenas, ou seja, a sua religião, Robertson enfatizou a necessidade de selecionar como foco de investigação apenas as duas doutrinas principais sobre as quais a religião indígena era, em sua opinião, balizada: "a essência de Deus" e "a imortalidade da alma", "deixando opiniões subordinadas e os detalhes de superstições locais a pesquisadores mais minuciosos" ${ }^{\prime 10} \mathrm{O}$ grau de descrição e detalhamento dos costumes indígenas é uma diferença essencial que é preciso, o quanto antes, ter em mente entre as macronarrativas de Robertson e Southey. Se Robertson buscava efetuar uma descrição panorâmica, Southey visava uma descrição minuciosa dos costumes dos nativos americanos. A descrição panorâmica, em última instância, permitia a comparação e delimitação do grau de civilização dos povos, possível porque o ser humano "vem originalmente da mão da natureza, é em todos os lugares o mesmo". Portanto, "depois de contemplar as rudes tribos americanas nessas várias

\footnotetext{
${ }^{108}$ SOUTHEY, Robert, op. cit., 1819, p. 199, grifos meus. No original: "[...] to learn weaving, that he might instruct them [os Moxos] on his return in one of the first arts of civilized life, and induce them to clothe themselves, as the first step towards civilization".

${ }^{109}$ HATTY, Suzanne E. \& HATTY, James. The disordered body: epidemic disease and cultural transformation. Albany: Suny, 1999, p. 19.

${ }^{110}$ ROBERTSON, William, op. cit., 1783b, p. 167. No original: "the being of God" [...] "the immortality of the soul", "leaving subordinate opinions, and the detail of local superstitions, to more minute inquirers".
} 
luzes, depois de ter um panorama de seus hábitos e costumes a partir de tantas posições diferentes, nada resta a não ser formar uma estimativa geral de seu temperamento, comparado com a de nações mais polidas".111 A descrição detalhada dos costumes e maneiras dos indígenas feitas por Southey, talvez por não ter a necessidade de fazer esse panorama que comprovava os estágios das sociedades, anteriormente realizado por Robertson, tendia a uma narração exaustiva dos costumes, chegando a abordar pontualmente não menos do que 60 tribos indígenas que viviam dentro do território brasileiro, paraguaio e argentino, pois "as variedades de caráter e maneiras entre as tribos selvagens são tão grandes como entre as nações civilizadas".112

Apontar as tribos americanas, que viviam em um estágio primitivo de caçadores como tão diversas quanto as sociedades civilizadas é uma das características que diferenciam radicalmente o emprego da teoria dos quatro estágios feito por Southey do de Robertson. As sociedades em estado selvagem, dentro da teoria dos estágios civilizacionais setecentista, tinham uma uniformidade que havia sido substituída nas sociedades comerciais por uma diversidade de características nacionais. ${ }^{13}$ As variedades contidas nas sociedades seriam consequência do passar do tempo e das mudanças de estágio. O desenvolvimento por estágios propunha que o movimento da humanidade iria da uniformidade e simplicidade para a diferença e complexidade. ${ }^{114}$ Existia uma polaridade entre a variedade encontrada nas nações europeias e a similaridade das tribos americanas, que eram tão parecidas que poderiam ser descritas como sendo idênticas. Para Robertson, dentro do continente americano não existia nenhuma diferença cultural entre seus habitantes, ele era uniforme em contraposição às visíveis diferenças culturais que, na Europa, mostravam-se através do conceito de nação. ${ }^{115}$

No caso de Southey, as particularidades de sua concepção de história ligadas a uma investigação minuciosa do passado permitiram uma reformulação desse aspecto central da teoria dos quatro estágios. Além disso, a grande

\footnotetext{
${ }^{111}$ ROBERTSON, William, op. cit., 1783b, p. 193. No original: "comes originally from the hand of nature, is every where the same", "After contemplating the rude American tribes in such various lights, after taking a view of their customs and manners from so many different stations, nothing remains but to form a general estimate of their character, compared with that of more polished nations".

${ }^{112}$ SOUTHEY, Robert, op. cit., 1819, p. 204. No original: "the varieties of character and manners among savage tribes are as great as among civilized nations".

${ }^{113}$ SEBASTIANI, Silvia, op. cit., 2013, p. 73.

${ }^{114}$ SEBASTIANI, Silvia, op. cit., 2013, p. 74

${ }^{115}$ SEBASTIANI, Silvia, op. cit., 2013, p. 95.
} 
quantidade de detalhes sobre o modo de vida das tribos indígenas levou a uma saturação da teoria dos estágios civilizacionais na medida em que o panorama e a classificação das sociedades - seja como caçadores, pastores, agricultores ou comerciantes - não respondia plenamente à necessidade de descrição complexa das sociedades indígenas nativas. Essa mudança de perspectiva analítica promoveu, em grande medida, uma secundarização, em History of Brazil, do modo de subsistência em detrimento do mapeamento dos costumes.

Não é possível negar que, assim como Robertson, Southey tivesse como horizonte final de análise a comparação. A descrição dos costumes e das maneiras seria também uma forma de interligar as sociedades no sentido de reunir as características que as uniam e que foram destruídas pelo tempo, e produzir uma analogia que permitisse elucidar alguns aspectos sobre o grau de civilização das sociedades que existiram em diferentes tempo e espaço. Essa possibilidade comparativa entre sociedades aparentemente um tanto distantes e diferentes permitia, por exemplo, a formulação de Southey sobre a inóspita situação da aldeia dos Abacaxis:

onde o jesuíta F. João de S. Paio outrora tinha reunido mil índios, mais de dois terços da população havia sido morta, em parte, de fato, pela varíola e pelo sarampo, mas em parte também por um mal mais permanente de um lago próximo, que é regularmente preenchido na época das cheias e durante o restante do ano fica estagnado e seca. Um grau de civilização elevado como a do antigo Egito deve ser atingido antes que tais circunstâncias físicas possam ser superadas. ${ }^{116}$

Os gregos também foram lembrados por Southey quando dissertava sobre os abipones: "como os gregos da Época Homérica consideravam o maior de todos os males permanecer insepulto; e, portanto, deleitavam-se em fazer flautas e trombetas dos ossos de seus inimigos e copos de seus crânios".117 As sociedades em geral seguiam uma direção bastante estável que permitia a comparação entre elas de modo a identificar o estágio civilizacional em que se encontravam, deixando o traço de características que só seriam en-

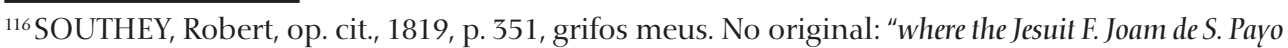
had once collected a thousand Indians, more than two thirds of the population had been cut off, partly indeed by the small pox and measles, but partly also by the more permanent evil of a near lake, which is regularly filled in the season of the floods, and during the remainder of the year stagnates and is dried up. A degree of civilization high as that of ancient Egypt, must be attained before such physical circumstances can be overcome".

${ }^{117}$ SOUTHEY, Robert, op. cit., 1819, p. 404, grifos meus. No original: "Like the Greeks of the Homeric age, they held it the greatest of all evils to be unburied; and therefore they delighted in making flutes and trumpets of their enemies bones, and drinking cups of their skulls".
} 
contradas em estágios mais ou menos civilizados. Essa estabilidade advinha da existência de regularidades que regiam o mundo natural e social e da partilha da mesma natureza humana por todos que viviam no planeta Terra.

Observar as maneiras dos povos permitia, igualmente, a comparação de fenômenos não registrados de forma escrita, como mostrava o caso dos bororos: "se uma de suas mulheres fosse capturada por portugueses, toda a sua família iria segui-la voluntariamente à escravidão. Esse apego às suas mulheres, que é tão raro entre os selvagens, parece indicar que eles eram da mesma raça que os goyas".118 $\mathrm{O}$ interesse pelos costumes e pelas maneiras, para Southey, auxiliava em um melhor entendimento das tribos brasileiras dentro da teoria dos estágios civilizacionais na medida em que oferecia indícios não registrados pela escrita para classificação das sociedades. Era por meio deles que Southey pôde afirmar que o relato das viagens feitas por Orellana e frei Gaspar de Carvajal ao longo do rio Amazonas, e que contribuiu para o surgimento da lenda do El Dorado, era falso:

Não é provável que estas tribos possuíssem ouro algum, nenhuma das tribos do Maranhão estava tão avançada para utilizá-lo. Onde quer que os índios americanos utilizassem ouro, encontraram-se habitações estacionárias, hábitos e vida sedentária, um governo regular, sacerdotes reunidos em corporação, e uma religião cerimoniada. Tribos errantes apanharão um grão de ouro como se fosse uma pedra de cor e o usarão pela sua beleza, mas devem deixar de ser errantes antes de usá-lo para fabricação de bugigangas ou utensílios. ${ }^{119}$

Existiam, portanto, elementos de comparação que muitas vezes só poderiam ser trazidos à narrativa com uma abordagem mais detida do modo de vida e organização indígena. Robertson claramente não tinha como objetivo a descrição exaustiva das tribos indígenas, porém não deixava de apontar algumas singularidades dessas sociedades, como a curiosa ausência de janelas em suas moradias. Entretanto, interrompe seu relato para frisar que "seguir os viajantes em outras circunstâncias minuciosas de sua descrição não está apenas abaixo da dignidade da história, mas seria estranho ao

\footnotetext{
${ }^{118}$ SOUTHEY, Robert, op. cit., 1819, p. 309-310, grifos meus. No original: "if one of their women were captured by the Portugueze, all her family would voluntarily follow her into bondage. This attachment to their women, which is so rare among savages, seems to indicate that they were of the same race as the Goyas".

${ }^{119}$ SOUTHEY, Robert, op. cit., 1810, p. 84-85, grifos meus. No original: "It is nor probable that these tribes had any gold, none of the tribes on the Maranham were so far advanced as to use it. Wherever the American Indians used gold, stationary habitations were found, habits of settled life, a regular government, a confederated priesthood, and a ceremonial religion. Wandering tribes will pick up a grain of gold, like a coloured stone, and wear it for its beauty; but they must cease to be erratic before they fabricate it into trinkets or utensils".
} 
objeto de minhas pesquisas". ${ }^{120}$ Acreditava que a descrição era a base para poder formar uma análise do dado e o que não poderia ser agrupado para explicar de maneira sistemática a organização da sociedade tinha um valor e interesse menor.

Não é novidade que a literatura de viagem sobre os indígenas americanos teve grande importância na determinação dos aspectos que seriam mais enfatizados na teoria dos quatro estágios, quando pensada em relação direta com o Novo Mundo e o desenvolvimento das sociedades que lá se encontravam. ${ }^{121}$ Esses relatos de viagem, profundamente imbuídos de histórias fantasiosas, auxiliavam na construção das temáticas de interesse, ao despertar a curiosidade do leitor para certos assuntos, e também serviam de material para as obras de síntese posteriores. Muitas narrativas seiscentistas de viagem definiram uma estrutura para a imaginação europeia, empregada pela maioria dos escritores subsequentes, em que figuravam a vasta e intricada natureza da terra e dos rios, a presença alusiva de povos nativos - enigmáticos quando não hostis, que desafiavam a morte por meio de flechas envenenadas ou festas canibais - e a atração por descobertas maravilhosas, quer dos impérios nativos de mulheres, das ligações fluviais insuspeitas, cidades de ouro ou maravilhas da natureza. ${ }^{122}$ Nessas intricadas visões da natureza tropical, descobriam-se também os nativos que eram, muitas vezes, confundidos com a natureza em si ou indistinguíveis dela por representarem uma enorme barreira para a expansão colonial. ${ }^{123}$

Por mais que numerosos autores que escreveram sobre o continente americano, como Acosta, Bartolomeu de Las Casas (1484-1566) e JosephFrançois Lafitau (1681-1746), tenham tido uma experiência direta da América e tenham igualmente insistido na centralidade dessa experiência para os seus relatos, a linguagem usada por eles foi construída por intelectuais europeus que nunca tinham deixado a Europa ou tido contato com um americano. Nesse sentido, a descoberta empírica da América não teve um impacto

\footnotetext{
${ }^{120}$ ROBERTSON, William, op. cit., 1783b, p. 158. No original: "to follow travellers in other minute circumstances of their description, is not only beneath the dignity of history, but would be foreign to the object of my researches".

${ }^{121}$ MEEK, Ronald, op. cit., 2010, p. 3.

${ }^{122}$ WHITEHEAD, Neil L. South America/Amazonia: the forest of marvels. In: HULME, Peter $\mathcal{E}$ YOUNGS, Tim (ed.). The Cambridge companion to travel writing. Cambridge: Cambridge University Press, 2010, p. 127.

${ }^{123}$ LANGFUR, Hal. The forbidden lands: colonial identity, frontier violence, and the persistence of Brazil's Eastern Indians, 1750-1830. Stanford: Stanford University Press, 2006, p. 289.
} 
nessas formas de expressão. Como todo contato em que não é possível estabelecer conexões com elementos culturais identificáveis, mobilizou o existente, que guiou o que seria descrito. A experiência da América não gerou uma nova relação entre Europa e América pela dificuldade no abandono do horizonte linguístico de referência já conhecido. Dessa forma, é preciso salientar que os escritores dos séculos XVI e XVII não estavam comprometidos com descrições acuradas do mundo americano, mas buscavam aproximá-lo de sua compreensão. Os fenômenos que reconheciam como sem precedente só poderiam tornar-se familiares e, portanto, inteligíveis nos termos de uma antropologia baseada na autoridade da tradição greco-romana. ${ }^{24}$ É dentro desse contexto que vemos Southey, mais de dois séculos depois, ainda respondendo, em History of Brazil, sobre o mito das amazonas, assim como o do El Dorado. Dava descrédito ao último e não duvidava por completo da possibilidade do primeiro. Mesmo havendo similaridades entre a descrição das amazonas americanas e as da Antiguidade, pensava que "sua existência não é a menos provável por causa disso e deve-se admitir também que a verdade provável é feita para parecer suspeita por sua semelhança com uma fábula conhecida". ${ }^{125}$

Esse cenário pré-configurado pelas narrativas de viagem está presente em diversas instâncias de History of Brazil e aliou-se com a narrativa dos costumes e maneiras na tentativa de oferecer um retrato do estágio civilizacional das sociedades. Nesse emaranhado de informações, torna-se natural a composição de um relato muitas vezes desconexo e com uma quantidade espantosa de detalhes. Southey, diferentemente de Robertson, não queria traçar um panorama da história do Brasil, mas erigir um monumento à posteridade que contivesse o maior número de informações possíveis. Por um lado, Southey distanciava-se de Robertson ao avalizar os detalhes e as aventuras propostos pela narrativa de viagem, por outro, esse mesmo gênero ajuda-o a aproximar-se de Robertson em relação à abordagem das maneiras dos povos selvagens. Ambos descrevem inúmeras diferenças entre os selvagens e os civilizados, como os utensílios, as roupas, os ornamentos, as casas, a alimentação, a dança, enfim, os costumes e as maneiras.

\footnotetext{
${ }^{124}$ PAGDEN, Anthony, op. cit., 1986, p. 4.

${ }^{125}$ SOUTHEY, Robert, op. cit., 1810, p. 608-609. No original: "their existence is not the less likely for that reason, and yet it must be admitted that the probable truth is made to appear suspicious by its resemblance to a known fable".
} 
Se Robertson inaugurou ou não uma tradição de abordagem da sociedade selvagem através da identificação do estágio civilizacional em que se encontrava, mediante a descrição de certos aspectos tidos como sinalizadores de civilização, é difícil de precisar, mas certamente contribuiu substancialmente para a difusão desse modelo social-etnográfico-comparativo de pesquisa. A partir do levantamento inicial realizado por Robertson da sociedade indígena americana e da prescrição de certos elementos como fundamentais para a análise do estado selvagem é que Southey desenvolveu a sua narrativa do desenvolvimento das sociedades pré-colombianas e do estado em que se encontravam. Assim como o relato de seu predecessor, o de Southey aparece sempre referenciado aos costumes europeus, pois estava à procura dos sinais de civilização e a sociedade europeia era tida como a única a ter chegado ao grau mais avançado de desenvolvimento. Essa referencialidade possibilitou mensurar o grau de civilização dos povos que passou em revista. Nesse contexto é que o leitor atual de History of Brazil encontra passagens aparentemente estranhas que apontam para a ausência de, por exemplo, guardanapos entre os selvagens. Southey tinha a convicção que seria melhor ter "uma nação cristã e civilizada" (a Christian and civilized nation) do que selvagens nômades sem conhecimento das letras, da pintura, escultura, dança, música e tantos outros benefícios permitidos por uma sociedade civilizada. ${ }^{126}$ Tendo essas bases é que analisou a história colonial brasileira.

\section{Referências bibliográficas}

ALLAN, David. Scottish historical writing of the Enlightenment. In: RABASA, José; SATO, Masayuki; TORTAROLO, Edoardo; WOOLF, Daniel (ed.). The Oxford history of historical writing, vol. 3: 1400-1800. Oxford: Oxford University Press, 2012.

BROWN, Marshall. Romanticism and Enlightenment. In: CURRAN, Stuart (ed.). The Cambridge companion to British romanticism. $2^{\mathrm{a}}$ edição. Cambridge: Cambridge University Press, 2010, p. 34-55.

BROWN, Stewart J. William Robertson (1721-1793) and the Scottish Enlightenment. In: Idem (ed.). William Robertson and the expansion of Empire. Cambridge: Cambridge University Press, 2008, p. 7-35.

CAÑIZARES-ESGUERRA, Jorge. Como escrever a história do Novo Mundo: histórias, epistemologias e identidades no mundo atlântico do século XVIII. São Paulo: Edusp, 2011.

\footnotetext{
${ }^{126}$ SOUTHEY, Robert. Church of England mission. Quarterly Review, vol. 32, 1825, p. 4.
} 
CRAIG, David M. Robert Southey and romantic apostasy: political argument in Britain 17801840. Royal Historical Society: Boydell Press, 2007.

CURRY, Kenneth. Southey. Londres: Routledge, 1975.

DIAS, Maria Odila da Silva. O fardo do homem branco: Southey, historiador do Brasil. São Paulo: Companhia Editora Nacional, 1974.

GERBI, Antonello. O Novo Mundo: história de uma polêmica (1750-1900). São Paulo: Companhia das Letras, 1996.

HATTY, Suzanne E. \& HATTY, James. The disordered body: epidemic disease and cultural transformation. Albany: Suny, 1999.

HAY, Denys. The historiographers royal in England and Scotland. Scottish Historical Review, vol. 30, 1951, p. 15-29.

HUMPHREYS, R. A. Robert Southey and his History of Brazil. Londres: Hispanic and Luso-Brazilian Council, 1978.

HONT, Istvan. The language of sociability and commerce: Samuel Pufendorf and the theoretical foundations of the "four-stages theory". In: PAGDEN, Anthony. The languages of political theory in early-modern Europe. Cambridge: Prentice Hall, 1990.

LANGFUR, Hal. The forbidden lands: colonial identity, frontier violence, and the persistence of Brazil's Eastern Indians, 1750-1830. Stanford: Stanford University Press, 2006.

LOPES, A. P. Leme. Da progressão dos costumes à história natural da humanidade: reflexões escocesas sobre a temporalidade histórica. História da Historiografia, n. 6, 2011, p. 158-170.

LOW, Dennis. The literary protégées of the lake poets. Hampshire: Ashgate, 2006.

MACLEOD, Emma. Revolution. In: GARRETT, Aaron \& HARRIS, James A. Scottish philosophy in the eighteenth century: morals, politics, art, religion. Oxford: Oxford University Press, 2015, p. 361-403.

MEEK, Ronald. Social science and the ignoble savage. Cambridge: Cambridge University Press, 2010.

O'BRIEN, Karen. Narratives of Enlightenment: cosmopolitan history from Voltaire to Gibbon. Cambridge: Cambridge University Press, 2005.

PAGDEN, Anthony. The fall of natural man: the American Indian and the origins of comparative ethnology. Cambridge: Cambridge University Press, 1986.

PHILLIPS, Mark Salber. Society and sentiment: genres of historical writing in Britain 17401820. Princeton: Princeton University Press, 2000.

PHILLIPSON, Nicolas. Providence and progress: an introduction to the historical thought of William Robertson. In: BROWN, Stewart J (ed.). William Robertson and the expansion of Empire. Cambridge: Cambridge University Press, 2008, p. 55-73.

PIMENTA, Pedro Paulo. Refinamento e civilização: ou como se colocar à altura de seu tempo. In: Idem. A imaginação crítica: Hume no século das luzes. Rio de Janeiro: Beco do Azougue, 2013.

PINTO, Alexandre Dias. The elusive manuscript of Robert Southey's History of Portugal. In: XXVII ENCONTRO DA APEAA. Novos Caminhos da História e da Cultura - Actas. Carcavelos, abril 2006. Lisboa: Apeaa $\mathscr{E}$ Ceap, Faculdade de Ciências Sociais e Humanas, 2007. 
POCOCK, J. G. A. Barbarism and religion: narratives of civil government, vol. II. Cambridge: Cambridge University Press, 2001.

. Barbarism and religion: barbarians, savages and empires, vol. 4. Cambridge: Cambridge University Press, 2005.

RAMINELLII, Ronald $\&$ SILVA, Bruno da. Teorias e imagens antropológicas na Viagem filosófica de Alexandre Rodrigues Ferreira (1783-1792). Bol. Mus. Para. Emílio Goeldi. Cienc. Hum., vol. 9, n. 2, Belém, mai-ago 2014, p. 323-342.

ROBERTSON, William. Preface. In: Idem. The history of America, vol. I. $4^{\text {a }}$ edição. Londres: Strahan; Cadell, 1783a.

Book IV. In: Idem. The history of America, vol. II. 4a edição. Londres: Strahan; Cadell, 1783b.

Book VII. In: Idem. The history of America, vol. III. $4^{\mathrm{a}}$ edição. Londres:

Strahan; Cadell, 1783c.

. Book IV. In: Idem. The history of America, vol. I. Dublin: Whitestone etc., 1777.

SEBASTIANI, Silvia. The Scottish Enlightenment: race, gender, and the limits of progress. Palgrave, 2013.

SHER, Richard B. The Enlightenment and the book. Chicago: Chicago University Press, 2006.

SISKIN, Clifford. The problem of periodization: Enlightenment, romanticism and the fate of system. In: CHANDLER, James (ed.). The Cambridge history of English romantic literature. Cambridge: Cambridge University Press, 2012.

SMITH, Adam. The Glasgow edition of the works and correspondence of Adam Smith, vol. V: Lectures on jurisprudence. Editado por R. L. Meek, D. D. Raphael e P. G. Stein. Indianapolis: Liberty Fund, 1978.

SOUTHEY, Charles Cuthbert (ed.). Life and correspondence of Robert Southey. Nova York: Harper $\mathcal{E}$ Brothers, 1855.

SOUTHEY, Robert. History of Brazil, vol. I. Londres: Longman, Hurst, Rees, and Orme, Paternoster-row, 1810.

. History of Brazil, vol. II. Londres: Longman, Hurst, Rees, and Orme, Paternoster-row, 1817.

. History of Brazil, vol. III. Londres: Longman, Hurst, Rees, and Orme, Paternoster-row, 1819.

An account of the Abipones, an equestrian people of Paraguay. Quarterly Review, vol. 26, n. 52, 1822.

Church of England mission. Quarterly Review, vol. 32, 1825.

Sir Thomas More: Or Colloquies on the Progress and Prospects of the Society, vol.

I. Londres: John Murray, 1829.

ST CLAIR, William. The reading nation in the romantic period. Cambridge: Cambridge University Press, 2007.

STOREY, Mark. "Bob Southey! - Poet Laureate": public and private in Southey's poems of 1816. In: PRATT, Lynda (ed.). Robert Southey and the contexts of English romanticism. Farnham: Ashgate, 2006. 
VARELLA, Alexandre C. A queda do homem civil: os antigos mexicanos e peruanos em The history of America de William Robertson. História Unisinos, vol. 2, n. 18, maio/agosto 2014, p. 248-259.

VARELLA, Flávia Florentino. Reunindo o passado: contextos discursivos e linguagens historiográficas na History of Brazil de Robert Southey. Tese de doutorado em História, Instituto de Filosofia e Ciências Humanas, Universidade Federal do Rio Grande do Sul, Porto Alegre, 2015, 323p.

WARTER, John Wood (ed.). Selections from the letters of Robert Southey, vol. 3. Londres: Longman, Brown, Green and Longmans, 1856a.

. Selections from the letters of Robert Southey, vol. 4. Londres: Longman, Brown, Green and Longmans, 1856b.

WHITEHEAD, Neil L. South America/Amazonia: the forest of marvels. In: HULME, Peter $\mathcal{E}$ YOUNGS, Tim (ed.). The Cambridge companion to travel writing. Cambridge: Cambridge University Press, 2010, p. 122-138.

Recebido: 14/02/2016 - Aprovado: 31/10/2016 